
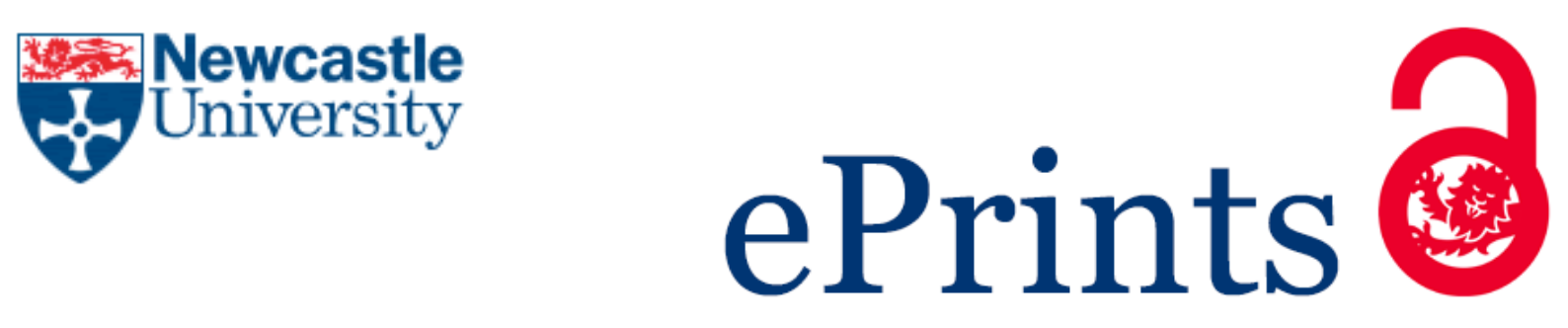

Whittle A. The paradoxical repertoires of management consultancy. Journal of Organizational Change Management 2006, 19(4), 424-436.

\title{
Copyright:
}

This article is (c) Emerald Group Publishing and permission has been granted for this version to appear here: http://eprint.ncl.ac.uk/pub details2.aspx?pub id=190876. Emerald does not grant permission for this article to be further copied/distributed or hosted elsewhere without the express permission from Emerald Group Publishing Limited.

The definitive version of this article, published by Emerald Group Publishing, 2006, is available at: http://dx.doi.org/10.1108/09534810610676635

Always use the definitive version when citing

Further information on publisher website:

http://www.emeraldinsight.com/

Date deposited:

$14 / 05 / 2015$ 
This is the author(s) personal version of the manuscript, as accepted after the review process but prior to final layout and copyediting by the publisher. The final version is published as:

Whittle, A. (2006) The paradoxical repertoires of management consultancy. Journal of Organizational Change Management 19(4): 424-443.

Readers are kindly asked to use the official publication in references.

\section{The Paradoxical Repertoires of Management}

\section{Consultancy}

Purpose: To outline paradoxes found in literature on management consulting and present a novel way of re-conceptualizing paradox using a performative or action-oriented approach to discourse.

Methodology/Approach: The approach is based on a theoretical reinterpretation of existing research findings on management consulting. Limited ethnographic data is also used to support the argument.

Findings: The article argues that paradoxes are an outcome of the many, often conflicting, interpretive repertoires used to understand management consulting. This suggests that paradoxes may never be resolved but instead may constitute a key resource for agents in affecting change. This idea is illustrated with reference to ethnographic data from a study of management consultants.

Research limitations/implications: The article suggests that a performative theory of discourse enables researchers to appreciate how and why paradoxes are reproduced in the context of organizational change.

Practical implications: Practitioners are seen to work within paradoxes, using conflicting interpretive repertoires as a toolkit for negotiating change. 
Originality/value: Proposes a novel way of viewing paradoxes by shifting the focus away from what paradoxical accounts reflect towards what they achieve in the context of interaction.

Article type: Conceptual paper.

Keywords: Management consulting, Organizational change, Paradoxes. 


\section{The Paradoxical Repertoires of Management}

\section{Consultancy}

\section{Introduction}

The popularity of the term paradox in management and organization studies is testimony to the general move away from rational and objective views of managing and organizing. With the so-called 'post-modern turn', terms such as tension, contradiction, irony, ambiguity and ambivalence now litter the literature. Paradoxes have been theorized in many different ways. Paradoxes have been seen as a medium and outcome of humour and irony (Hatch, 1997) and as a source of change to mental frames of reference (Westenholz, 1993). For some, paradoxes are not problems to be rectified by theories but rather present opportunities for building theories (Van de Ven and Poole, 1989). For others, paradoxes are simply a natural expression of the contradictions and dialectic tensions inherent in organizational life (Trethewey and Ashcraft, 2004; Putnam, 2004).

This article takes a different view of paradoxes. By employing a performative approach to discourse as outlined by Potter and Wetherell (1987), I suggest that paradoxes can be re-conceptualised as an outcome of the use of contradictory interpretive repertoires. $B y \mid$ reviewing and reinterpreting existing literature on the management consulting industry, I argue that paradoxes are less a problem to be resolved by change agents as resources through which actors can seek to understand, account for and affect organizational change. By way of illustration, the first paradox discussed in this article involves the tension experienced by consultants between advocating an idea and advising 
clients on how to manage the difficulties involved in its implementation. Existing research has tended to emphasise the importance of one aspect over the other, ignoring the paradoxes experienced by consultants who work within the tension. The direction of research has been focussed on delineating which is the most 'accurate' description (or 'effective' prescription) of what management consultants actually (or should) do. Yet by viewing the two approaches as competing repertoires that could be invoked by consultants or clients in order to account for and/or affect their everyday work, the paradox no longer needs to be 'resolved'. Indeed, I go on to present empirical data from an ethnographic study of management consultants in the UK to show how consultants draw on both repertoires to convince clients that their ideas are attractive enough to warrant interest and complex enough to require outside expert advice. This suggests that organizational change can occur within and through the use of paradoxical repertoires. It also suggests that future research could usefully focus on how paradoxical repertoires are used in practice as opposed to attempting to resolve paradoxes by uncovering a single most accurate or effective position.

The article is structured as follows. I first outline the paradoxical and contradictory accounts of the consultant-client relationship found in the literature on management consulting. In each case, I discuss the paradoxical positions, techniques and claims that scholars have suggested are assumed, asserted, expected or enacted on the part of the consultant. The discussion is organized into three sections relating to how consultants a) generate a market for their ideas, b) lay claim to knowledge and c) interact with clients. I move on to discuss the problems associated with attempts to 'resolve' the paradoxes by delineating the 'true' nature of consultancy or prescribe the 'best' or most 
'appropriate' consulting approach. I take a different stance by arguing that the paradoxes constitute a discursive resource that open up possibilities for those involved in change in organizations. I conclude by suggesting that paradoxical positions, claims and arguments can be seen as part of an interpretive repertoire or toolkit that agents can use to affect the process of management consulting. I also outline the practical consequences of this theoretical approach for researchers and practitioners of organizational change.

\section{On Consulting}

Despite a recent downturn in the market, management consultancy continues to play a significant role in the lives of organizations and employees across the globe (Crucini and paragraph contributes to the paper.

Kipping, 2001; Fincham and Clark, 2002; Salaman, 2002; Fincham and Clark, 2003;

Meriäinen et al., 2004). Few of us escape the impact of the consultancy industry (Salaman, 2002). Even where consultants are not directly involved, organizational change is often triggered by the bandwagon of fads and fashions pedalled by the ideas and advice industry (Abrahamson, 1991). Few therefore dispute that management consultancy deserves serious attention as a social and economic phenomenon. Indeed, a small but growing body of literature has begun to attend to management consultancy as an area of interest in its own right (e.g. Clark and Fincham, 2002; Kipping and Engwall, 2002). Given the power so often attributed to consultants as agents of organizational change, it is clearly important to develop an understanding of what consultants actually do. Accordingly, research has begun to build significant insights into the nature of consulting work. However, the divergent and often conflicting accounts generated by existing research have left us with many unresolved questions. My aim in this article is to a) 
outline some of the paradoxes generated by these conflicting accounts of what management consultants do and b) find a new way of viewing these accounts that will progress our understanding of paradox in organizations.

A short note on how I intend the paradoxes to be approached is appropriate here. Comment [HS6]: This paragraph could be edited or eliminated.

My intention is not to produce an exhaustive list of paradoxes. There are many conflicting accounts in the management consulting literature not discussed here. Further, the organization of the paradoxes into three sections is for heuristic purposes only and is not intended to reflect any fixed division of labour. For example, claims regarding knowledge and intervention approaches are undoubtedly involved in the marketing stage, just as marketing may itself be an ongoing activity. Nor is it my intention to suggest any normative or prescriptive judgement regarding either position within each paradox. As the discussion reveals, neither position comprises a complete description, solution or ideal scenario for consultant or client. My aim is therefore to highlight some of the paradoxical accounts found in existing literature before attempting to advance the debate by introducing the concept of interpretive repertoires.

\section{The marketing of consultancy}

In this section I outline a series of paradoxes that arise from conflicting accounts of how consultants market their services. Two questions are addressed here: How do consultants generate a market for their services? How do consultants generate future business from existing clients?

Paradox 1: Advocate and Advisor 
How do consultants generate a market for their services? Advocating the products, services and concepts on sale is one of the most obvious aspects of this process highlighted by existing research. For example, consultants have been observed attempting to persuade potential clients of the benefits they will deliver, the opportunities they will make available or the problems they will solve (Legge, 2002; Sturdy, 1997). Advocacy can also extend beyond specific client interactions to more general 'fashion-setting' work involving books, speeches, interviews, exhibitions and so on (Abrahamson, 1996).

A more critical strand of research has challenged the idea that consultants simply respond to pre-existing client needs, drivers or preferences. Rather, consultants are seen to actively constitute demand for their services through various rhetorical tactics (Alvesson, 1993; Fincham and Clark, 2002). Indeed, advocating constitutes a key marketing activity in an industry where clients are faced with significant uncertainty and ambiguity regarding the value-for-money, quality, reliability, effectiveness, knowledgebase and expertise of consultants and their services (Alvesson, 1993; Glücker and Armbrüster, 2003; Jones, 2003). It is therefore not surprising to find negative stereotypes antecedent. Sentence is wordy.

that portray consultants as potentially untrustworthy 'salespersons' pushing inefficient innovations (cf Abrahamson, 1991). Whether viewed sceptically or not, the 'consultant as advocate' is clearly involved in attempts to constitute the desirability of the products, services or concepts on sale.

While advocating a concept may be effective at stimulating a desire for action, research has suggested that this does not guarantee that the client will reject both the 'inhouse' option and rival consultancy firms. As scholars have pointed out, a welladvocated concept does not automatically generate 'fast bucks' for consultancies 
(Fincham, 1999; Fincham and Evans, 1999; Heusinkveld and Benders, 2003). This Comment [HS8]: "This" has no antecedent. suggests that consultants must also advise potential clients of the difficulties, problems and technicalities involved in achieving the benefits they advocate.

In Actor Network Theory terms, the 'consultant as advisor' attempts to make their consultancy services 'obligatory passage points'; the only route through which the client can achieve success (Bloomfield and Danieli, 1995). Here consultants generate not only enthusiasm and inspiration but also offer detailed methods for navigating the difficult path to the 'promised land', making them somewhat distinct from management gurus (Fincham and Evans, 1999; Fincham, 2002). According to some, then, this makes consultancy more about finding problems than finding solutions (Czarniawska and Mazza, 2003; Sturdy, 1997). The 'consultant as advisor' is therefore involved in constructing the problematic nature of the changes they promote and promise.

To sum up, existing research has produced conflicting accounts that portray consultants as either advocates or advisors. This generates a paradox surrounding whether Comment [HS9]: "This" has no antecedent. consulting involves the construction of desirable solutions or the construction of difficulties and problems.

\section{Paradox 2: Interested and Independent}

How do consultancies generate future business from existing clients? Consulting, like many other industries, relies heavily on repeat business or 'selling-on' (Jones, 2003; Sturdy, 1997). For some commentators, this 'stake' or 'interest' in selling their services means that consultants will always attempt to 'lock-in' clients by continuing and extending their work, irrespective of whether this benefits the clients (Shapiro et al., 
1993). Indeed, negative images of consultants portray them as parasites that feed off the insecurities of managers, deliberately generating dependency relationships in order to secure future business (Fincham and Clark, 2002; Shapiro et al., 1993; Sturdy 1997). For some, this explains why claims to offer a silver bullet (Gill and Whittle, 1992) and to transfer learning capabilities are unlikely because, among other thing, it would be counter-productive for the generation of future sales. Research has also revealed the range of tactics used to cultivate a dependency relationship with clients, including moving the benchmark and turning solutions into new problems (Czarniawska and Mazza, 2003; Fincham and Evans, 1999; Sturdy, 1997).

Others disagree with this straightforward positioning of consultants as interested only in sell-on. Some argue it is reductionist and inaccurate to describe consultants as manipulative con-men concerned only with the commercial interests of their employers (Heusinkveld and Benders, 2003; Jones, 2003; Robertson and Swan, 2003). Others suggest that revenue dependency means it is clients who dominate the relationship (Czarniawska and Mazza, 2003; Sturdy, 1997), as the case of Arthur Anderson and Enron highlights (Fincham and Clark, 2003). Clients and consultants are moreover unlikely to be naïve about perceptions of interest and may even use this during the bargaining process (Shapiro et al., 1993).

While certain consultants may be explicit about their interests, it is perhaps more common to find research that describes how consultants claim 'independence' and deflect, refute or resist attributions of interest. Within the more 'functionalist' literature it is assumed that consultants are (or should be) objective outside experts whose only interest lies in assisting the client (Werr and Styhre, 2003). Critical literature on the other 
hand has suggested that claims to 'independence' are simply another tactic used by consultants to enrol clients into purchasing their services. Bloomfield and Danieli (1995) for example describe how 'ontological gerrymandering' helped consultants to undermine the claims of others through reference to their 'interests' while obscuring or denying their own. Yet the appeal to 'independence' does not necessarily imply a 'duped' client. Bloomfield and Danieli (ibid) suggest that clients may actively cultivate this notion of 'independence' to legitimate their decisions. However, as we shall see below (see Paradox 5), such allegiances are not always desirable and productive for consultancy or client.

To sum up, existing research has produced conflicting accounts of the work of consultants, portraying them as either interested or independent. This generates a paradox surrounding whether consultants are seen to have a vested interest in cultivating dependency relationships or act as objective, independent advisors interested only in helping their clients.

\section{Consulting knowledge}

In this section I outline a series of paradoxes that arise from conflicting accounts of the knowledge-base involved in management consultancy. Two questions are addressed here: What forms of knowledge do consultants claim to employ? To what extent do consultants claim to adapt their knowledge to individual clients? 


\section{Paradox 3: Scientist and Storyteller}

What forms of knowledge do consultants claim to employ? Functionalist views present consultants as experts enlisted by clients for their ability to create, access and apply an esoteric and codified knowledge-base (Alvesson and Johansson, 2002; Werr and Styhre, 2003). While analogies with professions such as law, accounting and medicine are common, another popular professional metaphor is 'consultant as scientist'. Here consultants are thought to follow a scientific paradigm of analysis and intervention by using rational, objective and replicable techniques to produce scientific knowledge of the client organization and its environment.

Research has highlighted the trust engendered by the appearance of objectivity and independence associated with a scientific approach (Bloomfield and Danieli, 1995), a process known as ‘stake inoculation’ (Potter, 1996). Claims to scientific knowledge have also been found to help clients to appear progressive, informed and sophisticated in their decision-making (Alvesson, 1993). On the other hand, research has suggested that clients can find scientific knowledge alienating and make them wary of the dependency it tends to create (Shapiro et al., 1993), with negative repercussions for consultants in turn.

Within the literature, the view of consultancy as scientific knowledge-work has increasingly come under attack. Research has begun to highlight the forms of rhetoric (Alvesson, 1993), persuasion (Legge, 2002), drama (Case, 2002), fantasy (Jackson, 2002), emotion (Lundberg and Young, 2001) and storytelling (Clark and Salaman, 1996; Clark and Greatbatch, 2002) involved in the consultancy process. Common among this literature is a picture of consultants as narrators or storytellers. Storytelling diverges from the scientific paradigm because it draws on experiential knowledge and places more 
emphasis on plot than facts. This can extend beyond verbal interaction to include other symbolic forms such as glossy brochures, slick PowerPoint presentations, smart dress and futuristic technological artefacts (Bloomfield and Vurdubakis, 2002; Clark, 1995).

For some, storytelling presents advantages in actively encouraging participation and resonating with the practical experiences of client personnel (Fosstenløkken et al., 2003; Sturdy, 1997). Others have questioned the value of storytelling however. The value added by consultants can be questioned if stories lie too close to the practical experience of managers (Fincham, 1999; Shapiro et al., 1993). Clients may also be wary of trusting stories derived from single cases or different industries.

To sum up, existing research has produced conflicting accounts that portray consultants as scientists or storytellers. This generates a paradox surrounding whether consultants do (or should) act as objective experts who manipulate esoteric bodies of knowledge or, alternatively, act as symbolic performers, engaging their audience with captivating narratives.

\section{Paradox 4: Bespoke and Standardised}

To what extent do consultants claim to adapt their knowledge to individual clients? From a client's point of view, a bespoke approach is clearly desirable if it means recommendations informed by a detailed understanding of their organization that is in tune with the culture of their firm. In fact, research has suggested that even global consultancies adapt their offerings to different local contexts (Crucini and Kipping, 2001; Furusten 2001; Furusten and Bäcklund, 2000; Heller, 2002; Saint-Martin, 1998). Consultancies may themselves benefit from sell-on derived from their superior 
knowledge of the client organization (Sturdy, 1997) and the positive 'networked reputation' that comes with a track record of client satisfaction (Glücker and Armbrüster, 2003). Yet research has also questioned the feasibility and desirability of bespoke offerings for both client and consultant. For instance, bespoke offerings may forfeit the cost and quality advantages of more standardised, well-tested approaches (Jones, 2003). Time and money spent reinventing the wheel is not productive for consultant or client.

Research has also highlighted the role of centripetal forces towards standardisation. These enable consultancies to reap economies of scale and scope and to increase margins because less experienced consultants can be deployed with greater confidence (Jones, 2003), although this risks generating cynicism among clients (Shapiro et al., 1993). In addition, formalised and codified knowledge has been noted to facilitate shared learning between consultants and across projects and industries (Jones, 2003). Clients can also benefit from the confidence of knowing what will happen, when, and at what cost. 'Tried and tested' methods are also generally regarded as more reliable and consistent in their quality.

For some commentators, standardization can be unproductive for consultancy firms (Furusten, 2001) and can render their services amenable to replication by competitors (Jones 2003). Bäcklund (2001) suggests that sell-on may be adversely affected when clients feel their unique circumstances have been downplayed. Individual consultants may also view standardisation as an affront on their freedom and creativity and resist efforts to deskill their work (Jones, 2003). Kipping (2002) furthermore suggests that excessive standardisation renders consultancies inflexible when faced with changing fads and fashions. 
To sum up, existing research has produced conflicting accounts that portray consultancy as either a standardised or bespoke service. This generates a paradox surrounding whether consultants offer a standard and formalised approach or whether they instead provide a tailor-made service to clients.

\section{The client-consultant relationship}

In this section I outline a series of paradoxes that arise from conflicting accounts of the nature of the client-consultant relationship. Two questions are addressed here: How do consultants relate to power and politics in the client organization? Where does jurisdiction for decisions and actions lie?

\section{Paradox 5: Ally and Enemy}

How do consultants relate to power and politics in the client organization? Some commentators emphasise the role of consultants as 'friends' or 'allies' of certain groups (Bloomfield and Danieli, 1995; Fincham, 2003). Consultants are seen as 'agents of agents' used to legitimate or 'rubber stamp' the decisions of senior management (Shapiro et al., 1993; Fincham, 2002, 2003; Salaman, 2002). Allegiances such as these can be highly productive for consultants, providing them with momentum, resources and legitimacy within the client organization, especially if they enjoy high-level sponsorship (Fincham, 2003). Client groups can also benefit from employing consultants to influence outcomes in their favour.

Others have questioned the categorisation of consultants as 'ally'. Some have highlighted the ambivalence involved in their supposed allegiance, resonating with the 
ambivalence that exists in the role of managers as agents of capital (Sturdy, 1997; Fincham, 2003; Werr and Styhre, 2003). Disadvantages in the 'consultant as ally' position have also been noted. When political ties are recognised as such and the 'objectivity' of the consulting relationship is questioned, the legitimacy of both parties may be jeopardized. Allegiance with consultants can become a double-edged sword when the use of consultants is interpreted as a sign of managerial incompetence (Werr and Styhre, 2003). Sturdy (1997) even suggests that consultants can renew the managerial anxieties and problems they were first enlisted to assuage.

Other research has highlighted the view of consultants as 'foe' or 'enemy'. This body of literature has pointed to the range of tactics used by 'opposing' client groups (Sturdy, 1997; Fincham, 1999) including disagreement, deviation or overt conflict. For some client sponsors, opposition such as this represents a failure on the part of the consultants and a barrier to the change-in-progress. Consultants may similarly interpret resistance as an impediment to their work and a threat to their future relationship with the client. Other researchers have argued to the contrary, suggesting that this constitutes the very substance of their work. Consultants can be used to change the political topology of the client organization (Legge, 2002) or used as a scapegoat for allocating blame or diverting, deflecting or disguising opposition to the sponsoring group and their ideas (Fincham, 2003). Consultants acting or cast in the role of 'enemy' therefore do not inherently benefit or hinder the interests of consultant or client sponsor.

To sum up, existing research has produced conflicting accounts that portray consultants as ally or enemy. This generates a paradox surrounding whether consultants are likely to help or hinder the power and influence of client groups. 


\section{Paradox 6: Facilitator and Leader}

Where does jurisdiction for decisions and actions lie? Jurisdiction is a key issue in the consultant-client relationship. Whose definition of the problem is to be used? Who decides what course of action should be taken? Who is given the power to act? A common functionalist view of consultants is that of the authoritative 'leader', offering expert analysis, advice and intervention (Werr and Styhre, 2003). From a more critical perspective, consultants who present themselves as 'in charge' are merely attempting to legitimate their involvement, justify their fee and construct a positive sense of identity (Fincham and Clark, 2002; 2003; Jones, 2003). However, commentators have also noted that consultants often appear arrogant and insensitive in the eyes of clients (Fincham and Clark, 2002; Shapiro et al., 1993) and, given their revenue dependency, have questioned the ability of consultants to really drive the agenda (Fincham, 2003; Sturdy, 1997). Thus while both consultancy and client can clearly benefit from a strong leadership on the part of consultants, this may not always be possible or desirable for either party.

In contrast, research has also highlighted how consultants assume or are expected to assume a more ‘facilitative’ role (Fincham, 2003). Here the powers of decision-making and action are assigned largely to the client. Consultants may be brought in merely to fill resource shortages on a project already initiated by the client organization (Werr and Styhre, 2003), or may deliberately enrol internal champions or high-level sponsorship to avoid being the central actor (Fincham, 2003). Clients benefit from feeling empowered to act and gaining a sense of ownership and commitment to decisions. That said, clients may 
also suffer from a lack of progress or 'paralysis by analysis' and crave more speedy and proactive intervention (Shapiro et al., 1993).

To sum up, existing research has produced conflicting accounts that portray consultants as leader or facilitator. This generates a paradox surrounding whether consultants do or should play a 'driving seat' or 'back seat' role in affecting organizational change.

\section{Debating paradox}

So far I have highlighted a series of paradoxes arising from the conflicting accounts of management consultancy found in existing literature. Research has produced conflicting descriptions of how management consultancy is marketed, the nature of consultancy knowledge, and the relationship between consultant and client. How can we best understand these paradoxical accounts? Can and should they be resolved? There are several approaches to these questions. One is to 'sort through' these paradoxical accounts to attempt to find the 'true' nature of consulting work. Another alternative is to attempt to prescribe the 'best' or most 'appropriate' approach, whether from the perspective of consultant or client.

Numerous problems beset both of these approaches. First, to delineate the 'true' nature of consulting work within each paradox would require that certain accounts be designated as 'false'. This seems an overly sceptical and cynical view of the accounts produced by researchers and the participants of their studies. Second, to produce criteria upon which to judge the validity and reliability of these various accounts would also prove a difficult task. What research methods produce the most valid picture of 
consultancy? Do consultants or clients produce more accurate and reliable accounts of the consultancy process? Addressing these questions is hampered among other things by the multiplicity of accounts produced within client and consultant groups and between different contexts, not to mention the competing methodologies and epistemological assumptions used by researchers.

A third problem with attempting a single definitive description of consulting work relates to its dynamic and ongoing accomplishment. Attempting to capture a definitive account of consulting work 'for all times' seems misplaced given the ongoing, open, reflexive and situated processes through which consulting work is achieved (Berglund and Werr, 2000; Fincham, 1999; Fincham and Clark, 2002; Jones, 2003; Sturdy, 1997). Fourth, in more 'functionalist' terms, attempting to delineate the 'best' or 'most effective' approach for client or consultant is also problematic. As the discussion has revealed, neither position in the paradoxes constituted a panacea or ideal scenario for consultant or client. Both positions have been noted to generate distinct problems as well as benefits for both parties.

It is clear that attempting to delineate an authoritative definition of the 'true' nature or 'best' approach to management consultancy is an unproductive if not impossible task. An alternative approach could instead be to search for the most 'appropriate' consulting approach. Here the divergence in accounts of consultancy is attributed to the fact that consulting is itself diverse and varied according to client base, sector, geographical location and intervention technique. An engineering consultancy, for instance, might be more likely to lay claim to a scientific knowledge base than a 'culture change' consultancy. This 'contingency' approach renders the paradoxes less of a 
problem and more of a natural expression of the various, sometimes contradictory, niches within a heterogeneous industry.

Do the paradoxes therefore describe different positions adopted by consultants attempting a contingent 'fit' with their geographic location, sector or client base? This explanation may well be true in part, but cannot explain the existence of contradiction within specific consultant-client relationships. For example, individual consultants have been noted to produce conflicting explanations, knowledge claims and intervention approaches in different contexts (Werr and Styhre, 2003) and even within the same interaction (Berglund and Werr, 2000; Jones, 2003). These findings require serious attention as opposed to being prematurely dismissed, resolved or explained away.

Given these problems with attempts to reconcile the paradoxes according to measures of truth, efficacy or contingent fit, there remains a need for alternative approaches to understanding the paradoxes. The concept of 'discourse' appears to offer a useful theoretical framework for addressing this task. The concept has in fact already been deployed in management consulting research. Werr and Styhre (2003) use the term 'discourse' to refer to the broad institutional contexts and trends that inform, shape and frame the nature and meaning of management consultancy. The authors highlight the way in which discourses make possible and legitimate the formation of particular clientconsultant relationships. This draws on a predominantly 'muscular' or 'constitutive' theory of discourse (Alvesson and Karreman, 2000), where discourse is understood to shape the ideas, practices, meanings and beliefs of actors. Whereas Werr and Styhre (2003) do mention that discourses can act as 'resources' for constructing the clientconsultant relationship, the purposeful and strategic aspects of discourse are underplayed. 
My aim is to place the purposeful and strategic elements of discourse centre stage by viewing discourse as a 'resource'. To do this I will employ the 'performative' or 'action oriented' framework provided by Potter and Wetherell (1987) to re-examine the issue of paradox in organizations.

\section{Understanding paradox using interpretive repertoires}

The concept of interpretive repertoires refers to an approach to the study of discourse that draws attention to its performative characteristics, that is, what discourse performs or achieves for the actor in a particular social setting. The term interpretive repertoire is used to refer to a more or less coherent collection of styles, metaphors and rhetorical devices used to characterise and evaluate actions, events and other phenomenon in the context of interaction (Potter and Wetherell, 1987). This approach to discourse analysis is particularly valuable for its ability to understand the role of contradiction and paradox. For instance, Wetherell, Stiven and Potter's (1987) study of equal opportunities discourse gathered from qualitative interviews reveals the paradoxes created and sustained by respondents as they simultaneously drew on 'egalitarian' and 'fairness' repertoires at the same time as restoring and justifying inequality by appealing to the 'biological inevitability' and 'practical necessities' of child rearing. This created a paradox wherein respondents both wholeheartedly supported social change but also appealed to 'practical considerations' which effectively neutralised the impetus for change. In this case, contradictory repertoires were used to appeal to socially progressive ideas (equality of opportunity) whilst justifying the status quo (inequality) in ways which both maintained a positive identity for the respondent and negated the need for adjustment (at a personal, 
organizational or political level). The point of research using an interpretive repertoire approach is thus not to search for the (singular and fixed) 'attitudes' or 'positions' held by respondents but to examine when, why, how and with what effect paradoxical repertoires might be sustained or challenged.

The interpretive repertoire approach offers a novel way of re-examining the paradoxes discussed earlier. The paradoxical accounts can now be seen as competing repertoires for describing, performing and evaluating the marketing of consultancy, the nature of consultancy knowledge and the relationship between consultant and client. It is therefore not surprising that research has produced a paradoxical array of accounts of what management consultants do. From a performative discourse perspective, these paradoxes reflect the array of different, often contradictory, interpretive repertoires that are available to actors involved in the management consulting process.

Before I move on to illustrate this approach by examining empirical data from a study of UK management consultants, a short discussion of the theoretical assumptions underlying the interpretive repertoire approach seems relevant. First, to emphasise the performative aspects of discourse is not to reduce discourse to a mere performance, unconnected or incidental to the 'real' work of consultancy, or at least restricted to events such as the sales pitch. This reproduces the commonplace misunderstanding that divides actions and words and ignores the ways in which discourse constitutes action, that is, how discourse plays an active role in the social accomplishment of management and organization (Grant, Keenoy and Oswick, 1998; Potter and Wetherell, 1987). This issue is discussed further in the next section. 
Second, the concept of interpretive repertoires is not also intended to imply that actors are always politically motivated and consciously aware 'impression managers'. Emphasising the performative aspects of discourse does not reduce consultants to slick 'con-men'. The skilful use of discourse can instead be seen as simply part of the 'habitus' of the consultancy field, that is, "the ability of actors to manoeuvre in a culturally competent way” (Alvesson, 1994: 536). This can apply to clients and other groups as much as consultants. The paradoxes outlined in this paper can therefore be seen as reflecting the rich and often contradictory repertoires employed by consultants, clients and others (including researchers) to describe and affect the management consulting process.

Finally, while interpretive repertoires have tended to be used to analyse spoken interaction, which of course comprises a large proportion of the consultancy process, a broader focus on 'discourse' need not be restricted to linguistic interaction. A wider definition enables the texts, artefacts, technologies and practices involved in management consultancy to also be understood as interpretive repertoires.

\section{Interpretive repertoires in action}

Having outlined the theory underlying the concept of interpretive repertoires, I will now move on to outline the advantages offered by this approach in reinterpreting the paradoxes discussed in this article. One key advantages lies in the fact that interpretive repertoires do not reflect any enduring attitude, belief or behaviour on the part of the actor. The reproduction of an interpretive repertoire by a consultant, therefore, does not necessarily reflect their underlying approach, identity or motive. The advantage of this 
approach is that it enables an understanding of how and why consultants (and others) may reproduce conflicting repertoires in the context of achieving their work. For instance, consultants have been found to reproduce contradictory knowledge claims, laying claim to both standardised and bespoke knowledge (Berlund and Werr, 2000; Jones, 2003). By viewing these accounts given in research interviews and client encounters as interpretive repertoires, the contradictory and paradoxical claims do not pose a stumbling block to delineating what consultants 'really' do, what type of knowledge they 'really' employ etc. Rather, it suggests that the skilful use of paradoxical repertoires may actually comprise a key attribute of the achievement of consulting work. Paradox therefore becomes a medium and outcome of consulting-led change.

An example of paradoxical repertoires in action might help to illustrate this idea. The author conducted a nine month ethnographic study of FlexiTeam, a group of ten management consultants employed by a UK-based telecommunications company. FlexiTeam sold 'flexible working' advice, helping clients to utilise the potential of technology to enable work to be conducted 'anywhere/anytime'. The research found that paradoxes were a recurrent feature of the consultants' working lives. One particular example gathered during non-participant observation of a client meeting would help to illustrate the first paradox discussed earlier (advocate vs advisor). The meeting was organized by Steve and Claire, both senior managers of a prospective client organization (an advertising agency). They had invited Barry, a FlexiTeam consultant, to their office to discuss the possibility of implementing flexible working. While Steve and Claire both expressed their interest in flexible working, they also expressed doubts and concerns. Barry used this ambivalence to draw upon two contradictory repertoires that would help 
him convince them to enlist the advice of FlexiTeam. Barry began by explaining how difficult flexible working was to 'get right'. Managers, he warned, could be unable to think outside their current 'presenteeism' and unwilling to trust their staff. Tactic knowledge sharing could be lost in the absence of 'watercooler' conversations. Teams could fail to 'gel' without face-to-face contact. In short, organizations could easily generate more problems than they solved by implementing flexible working. Yet by presenting flexible working as 'problematic', Barry was able to construct an appetite for the consulting 'tools' available if they enlisted FlexiTeam's advice, such as management training, knowledge management systems, 'best practice’ seminars and culture change workshops. The repertoire of 'advisor' clearly facilitated his work as a consultant.

However, Barry also enacted the repertoire of 'advocate' by emphasising the benefits of flexible working, to ensure that the difficulties were not overstated and the desirability of the idea was not lost. Flexible working, he explained, was easy, natural and inevitable: there was no 'barrier' to generating success (even though he had just detailed the problems, difficulties and inertia it involved). He ended by reciting an evangelical story of how, as a flexible worker himself, he is able to avoid a long commute to work and mow his lawn during his lunch break if he so wishes. Steve and Claire reacted with almost jealous awe and were clearly impressed. In other words, the 'advocate' repertoire certainly seemed to facilitate Barry's work even though it contradicted his earlier 'warning tale'. Thus by drawing on the contradictory repertoires of consultant as advocate and advisor, Barry was able to construct an appetite for outside advice by portraying flexible working as problematic while maintaining the appetite for the idea by 
presenting flexible working as desirable. The work of the consultant was thereby achieved by working in and through the paradox.

The concept of interpretive repertoires can also be used to analyse the role of the client in the consultancy process. Repertoires do not 'belong' to particular groups and clients are themselves active in using interpretive repertoires. Take for example the repertoires used by Barry in the observation data described above. These could be reappropriated by client employees to resist and undermine his consulting activities, for instance by highlighting the failure of promises he constructed as 'advocate' (“consultants always lure managers with unrealistic visions”) or translating the difficulties he described as 'advisor' into insurmountable hurdles ("it will never work here because ...”). Indeed, McGivern (1983) has observed how clients influenced the consultancy process by employing contradictory repertoires, first criticising consultants for being too directive, then criticizing them for not being directive enough. From a performative discourse perspective, this paradoxical use of the repertoires 'leader' and 'facilitator' enabled the client to not only describe but also affect the consultancy relationship. Indeed, the behaviour, style and approach taken by the consultant changed accordingly. Repertoires can therefore be used by clients to assist and support their agenda or alternatively to resist, deflect, undermine or neutralise moves they dislike by interrogating the motives, knowledge claims and intervention approach of the consultants (Sturdy, 1997). For example, clients may:

- employ the 'advocate' repertoire to remind consultants of their heady promises,

- draw on the 'interested' repertoire to undermine consulting advice when it is disliked, 
- appeal to the 'scientist' repertoire to question the objectivity and reliability of their findings,

- call upon the 'bespoke' repertoire to request a service that is adapted to their needs,

- use the 'ally' repertoire to convince others that consultants are on their side,

- utilize the 'leader' repertoire to demand the consultants take a more proactive role.

The key advantage of the concept of interpretive repertoires thus lies in its ability to appreciate how and why actors may remain within paradoxes, perhaps never resolving them once and for all. Clients, like consultants, have been found to reproduce paradoxical repertoires. With a performative discourse perspective, we are able to understand how and why varied (and sometimes contradictory) interpretive repertoires might be used to shape the trajectory of the consultancy process. The implications for practitioners and researchers are considered in more detail next.

\section{Implications for practitioners}

The performative view of discourse is a highly practical approach in terms of informing the work management consultancy practitioners and others implicated in the consultancy process. Interpretive repertoires do not simply describe or account for action but also play an active role in constructing events and outcomes. As repertoires for action as well as description, interpretive repertoires enable actors to:

- define problems

- construct allegiances 
- make decisions

- accomplish events

- generate ideas

- implant new practices

Drawing on available interpretive repertoires offers practitioners a rich vocabulary for actively influencing the consultancy relationship. Through the skilful use of interpretive repertoires, actors can describe, explain, justify, request, command, assume, encourage, praise, blame, persuade, influence and make sense of management consultancy. As we saw above, consultant Barry was able to convince potential clients to buy into the idea of flexible working and also buy advice about implementing flexible working by drawing on the paradoxical repertoires of consultant as 'advocate' and 'advisor'.

Interpretive repertoires can also enable consultants and clients to think through key questions such as 'How should we manage this situation?', 'How should be interpret this information?', 'How can we enrol others into our project?' or 'What should we do next?' For instance, above I presented a list of how clients could use the interpretive repertoires discussed in this article to steer the consulting relationship. Furthermore, the skills involved in using discourse strategically and tactically endow actors with power potential. For example, culturally competent actors are more likely to find their knowledge-claims accepted, their identities confirmed, their actions tolerated and their authority respected (Alvesson, 1994). Thus it is in and through discourse, broadly conceived, that management consultancy is accomplished.

The concept of interpretive repertoires suggests a need to rethink how practitioners might approach the paradoxes outlined in this article. From a performative 
perspective, the paradoxes no longer comprise a problem to be solved by delineating the one best approach. Reconciling the paradoxes may be neither necessary nor desirable. On the contrary, the existence of paradox may actually facilitate as opposed to threaten or disrupt the work of change agents. To prematurely deny, refuse or constrain alternative repertoires could in fact limit their ability to explore alternative identities, practices and techniques. For instance, if Barry had drawn exclusively upon an 'advocate' repertoire, the prospective client could easily have been left excited and enticed by the idea of flexible working but unwilling to pay for advice. Similarly, the 'advisor' repertoire alone would have left the client managers aware of the pitfalls of flexible working but unconvinced of its value. In both cases it is unlikely that Barry would have been able to enlist the client. The ability to switch between competing repertoires is therefore likely to comprise a significant aspect of change expertise and a significant source of dynamism and flexibility. This suggests that the work of change agents may in fact be undertaken within the paradoxes outlined in this article.

Several points of clarification are needed here. First, to emphasise the existence and function of multiple interpretive repertoires is not to prescribe the employment of conflicting repertoires. Consistency is likely to be an important quality of consultancy and management in general. Second, even where conflicting interpretive repertoires are skilfully employed, this is unlikely to resolve all the tensions and ambiguities of the consultancy relationship. Interpretive repertoires can be used to solve problems and resolve conflicts but can also create tensions and contradictions of their own (Potter and Wetherell, 1987). Nor are interpretive repertoires universally applicable. The popularity, legitimacy and effectiveness of a repertoire may change between contexts and over time. 
Finally, the effect of a repertoire is not guaranteed. The accomplishment of a repertoire is always open and deferred because it ultimately relies on acceptance and confirmation by the other participants of the interaction.

In sum, the concept of interpretive repertoires enables practitioners to understand how the skilful use of discourse that works within paradoxes can constitute a powerful tool in navigating and negotiating the consultancy relationship.

\section{Implications for researchers}

The theoretical framework provided by the concept of interpretive repertoires highlights several issues for researchers interested in the management advice industry. From this perspective, accounts produced during interviews or fieldwork observations are no longer taken to reflect the underlying approach, belief or technique used by consultants or clients. This enables researchers to understand how and why actors produce accounts that are sometimes contradictory and paradoxical because of their reflexive awareness of what may be appropriate and/or advantageous in a given context, whether a client interaction or an interview with a researcher. For instance, respondents can be seen as skilled at producing accounts that a) portray themselves in a positive light, b) reproduce accepted and respected versions of what is right and wrong, and/or c) bring the audience 'on side', whether or not these repertoires reflect any underlying attitude, behaviour, emotion or stance. By analysing these accounts for what they construct or achieve for those producing the account, the existence of paradoxical accounts then becomes less of a problem to be resolved and more a phenomenon to be understood in its own right. The 
key questions instead become: How and why do particular repertoires achieve salience and acceptance in particular contexts?

\section{Conclusion}

What do management consultants do? A definitive answer to this question seems at first sight to be hindered by the contradictory accounts of management consultancy found in existing literature. This has generated a puzzle for scholars and practitioners alike. How can we make sense of these paradoxical accounts? I have suggested that attempts to delineate the most accurate, effective or appropriate position are limited in their ability to understand the open, reflexive, ongoing and sometimes contradictory accomplishment of management consultancy.

By viewing the paradoxical accounts found in existing literature as different discourses available to actors involved in the consulting process, a new way of conceptualising the paradoxes has been possible. In particular, by drawing on a performative approach to discourse found in the concept of 'interpretive repertoires' (Potter and Wetherell, 1987), I have suggested that the paradoxical accounts can be analysed for what they achieve as opposed to what they reflect about the nature of management consultancy. In other words, repertoires can be drawn upon by actors to achieve something in the context of interaction without necessarily reflecting any underlying or stable stance, attitude, approach or behaviour. The existence and use of paradoxical repertoires therefore becomes less of a problem to be solved than a resource for interpretation and action. For instance, the ethnographic data presented above revealed how consultant Barry drew on the paradoxical repertoires of consultant as 
'advocate' and 'advisor' to market his services to prospective clients. The employment of these contradictory repertoires helped to convince the client managers that the idea on sale was both desirable and problematic. This suggests that the ability to draw on paradoxical repertoires comprises a key competence for actors involved in negotiating change. Accordingly the paradoxes no longer need to be resolved but instead comprise a 'tool-kit' that offer resources to change agents. This suggests that paradoxical repertoires are not only resources for talking about consulting-led change but can also constitute resources for doing organizational change.

\section{References}

Abrahamson, E. (1991), “Managerial fads and fashions: The diffusion and rejection of innovations”, Academy of Management Review, Vol. 16 No. 3, pp. 586-612.

Abrahamson, E. (1996), “Management fashion”, Academy of Management Review, Vol. 21 No. 1, pp. 254-85.

Alvesson, M. (1993), “Organizations as rhetoric: Knowledge-intensive firms and the struggle with ambiguity”, Journal of Management Studies, Vol. 30 No. 6, pp. 997-1015.

Alvesson, M. and Johansson, A. (2002), "Professionalism and politics in management consultancy work”, In Clark, T. and Fincham, R. (Eds), Critical Consulting. Oxford, Blackwell, pp. 228-246.

Alvesson, M. and Karreman, D. (2000), "Varieties of discourse: On the study of organizations through discourse analysis”, Human Relations, Vol. 53 No. 9, pp. $1125-49$. 
Bäcklund, J. (2001), “Standardization and local adaptation: An analysis of management consultancies tenders to the public sector”, SCORE Rapportserie, 2001,11.

Berglund, J. and Werr, A. (2000), “The invincible character of management consultant rhetoric: How one blends incommensurates while keeping them apart”, Organization, Vol. 7 No. 4, pp. 633-55.

Bloomfield, B. and Danieli, A. (1995), “The role of management consultants in the development of information technology: The indissoluble nature of socio-political and technical skills”, Journal of Management Studies, Vol. 32 No. 1, pp. 23-46.

Bloomfield, B. and Vurdubakis, T. (2002), “The vision thing: Constructing technology and the future in management advice”, In Clark, T. and Fincham, R. (Eds), Critical Consulting, Oxford, Blackwell, pp. 115-129.

Case, P. (2002), "Virtual stories of virtual working: Critical reflections on CTI consultancy discourse”, In Clark, T. and Fincham, R. (Eds), Critical Consulting, Oxford, Blackwell, pp. 93-114.

Clark, T. (1995), Managing Consultants: Consultancy as the Management of Impressions, Buckingham, Open University Press.

Clark, T. and Fincham, R. (Eds) (2002), Critical Consulting, Oxford, Blackwell.

Clark, T. and Greatbach, D. (2002), “Knowledge legitimation and audience affiliation through storytelling: The example of management gurus”, In Clark, T. and Fincham, R. (Eds), Critical Consulting, Oxford, Blackwell, pp. 152-171.

Clark, T. and Salaman, G. (1998), “Creating the 'right' impression: Towards a dramaturgy of management consultancy”, Services Industry Journal, Vol. 18 No. 1, pp. 18-38. 
Crucini, C. and Kipping, M. (2001), "Management consultants as global change agents? Evidence from Italy”, Journal of Organizational Change Management, Vol. 14 No. 6, pp. 570-89.

Czarniawska, B. and Mazza, C. (2003), “Consulting as a liminal space”, Human Relations, Vol. 56 No. 3, pp. 267-90.

Denning, S. (2000), The Springboard: How Storytelling Ignites Action in Knowledge-Era Organizations, Boston, Butterworth-Heinemann.

Fincham, R. (1999), “The consultant-client relationship: Critical perspectives on the management of organizational change”, Journal of Management Studies, Vol. 36 No. 3, pp. 335-51.

Fincham, R. (2003), “The agent's agent: Power, knowledge and uncertainty in management consultancy”, International Studies of Management \& Organization, Vol. 32 No. 4, pp. 67-86.

Fincham, R. and Clark, T. (2002), "Introduction: The emergence of critical perspectives on consulting”, In Clark, T. and Fincham, R. (Eds), Critical Consulting, Oxford, Blackwell, pp. 1-20.

Fincham, R. and Clark, T. (2003), “Management consultancy: Issues, perspectives and agendas”, International Studies of Management \& Organization, Vol. 32 No. 4, pp. 3-18.

Fincham, R. and Evans, M. (1999), “The consultants’ offensive: reengineering - from fad to technique”, New Technology, Work and Employment, Vol. 14 No. 1, pp. 32-44.

Fosstenløkken, S. et al (2003), “Knowledge development through client interaction”, Organization Studies, Vol. 24 No. 6, pp. 859-79. 
Furusten, S. (2001), “Consulting in legoland - The jazz of small-scale management consultation in the improvisation on standards”, SCORE Rapportserie, 2001,3.

Furusten, S. and Bäcklund, J. (2000), “In the shadow of American stars - On American dominance and the Americanisation of the Swedish management consultancy field”, SCORE Rapportserie, 2000,3.

Gill, J. and Whittle, S. (1992), “Management by panacea: Accounting for transience”, Journal of Management Studies, Vol. 30 No. 2, pp. 281-295.

Glücker, J. and Armbrüster, T. (2003), Bridging uncertainty in management consulting: The mechanisms of trust and networked reputation”, Organization Studies, Vol. 24 No. 2, pp. 269-297.

Hatch, M. J. (1997), "Irony and the social construction of contradiction in the humor of a management team”, Organization Science, Vol. 8 No. 3, pp. 275-288.

Heller, F. (2002), "What next? More critique of consultants, gurus and managers”, In Clark, T. and Fincham, R. (Eds), Critical Consulting, Oxford, Blackwell, pp. 260272.

Heusinkveld, S. and Benders, J. (2002), “Between professional dedication and corporate design: Exploring forms of new concept development in consultancies”, International Studies of Management \& Organization, Vol. 32 No. 4, pp. 104-22.

Jackson, B. (2002), “A fantasy theme analysis of three guru-led management fashions”, In Clark, T. and Fincham, R. (Eds), Critical Consulting, Oxford, Blackwell, pp. 172-189.

Jones, M. (2003), “The expert system: Constructing expertise in an IT/management consultancy”, Information and Organization, Vol. 13, pp. 257-84. 
Kipping, M. (2002) "Trapped in their wave: The evolution of management consultancies”, In Clark, T. and Fincham, R. (Eds), Critical Consulting, Oxford, Blackwell, 28-49.

Kipping, M. and Engwall, L. (2002), Management consulting: The emergence and dynamics of a knowledge industry, Oxford, Oxford University Press.

Legge, K. (2002), “On knowledge, business consultants and the selling of total quality management”, In Clark, T. and Fincham, R. (Eds), Critical Consulting, Oxford, Blackwell, pp. 74-91.

Lundberg, C. and Young, C. (2001), “A note on emotions and consultancy”, Journal of Organizational Change Management, Vol. 14 No. 6, pp. 530-38.

Meriäinen, S. et al (2004), “Management consultant talk: A cross-cultural comparison of normalizing discourse and resistance”, Organization, Vol. 11 No. 4, pp. 539-64.

Potter, J. (1996), Representing Reality: Discourse, Rhetoric and Social Construction, Thousand Oaks, CA, Sage.

Potter, J. and Wetherell, M. (1987), Discourse and Social Psychology: Beyond Attitudes and Behaviour, London, Sage.

Putnam, L. (2004), "Dialectic tensions and rhetorical tropes in organizations", Organization Studies, Vol. 25 No. 1, pp. 35-53.

Saint-Martin, D. (1998), "The New Managerialism and the Policy Influence of Consultants in Government: An Historical-Institutionalist Analysis of Britain, Canada and France”, Governance, Vol. 11 No. 3, pp. 319-56. 
Salaman, G. (2002), "Understanding advice: Towards a sociology of management consultancy”, In Clark, T. and Fincham, R. (Eds), Critical Consulting, Oxford, Blackwell, pp. 247-259.

Shapiro, E. et al (1993), “Consulting: Has the solution become part of the problem?”, Sloan Management Review, Vol. 34 No. 4, pp. 89-95.

Sturdy, A. (1997), “The consultancy process - an insecure business?”, Journal of Management Studies, Vol. 34 No. 3, pp. 389-413.

Trethewey, A. and Ashcraft, K. (2004), "Practicing disorganization: The development of applied perspectives on living with tension”, Journal of Applied Communication Research, Vol. 32 No. 2, pp. 81-88.

Ven de Ven, A. and Poole, M. S. (1989), "Using paradox to build management and organization theories”, Academy of Management Review, Vol. 14 No. 4, pp. 562578.

Werr, A. and Styhre, A. (2003), "Management consultants - friend or foe? Understanding the ambiguous client-consultant relationship”, International Studies of Management \& Organization, Vol. 32 No. 4, pp. 43-66.

Westenholz, A. (1993), "Paradoxical thinking and change in the frames of reference”, Organization Studies, Vol. 14 No. 1, pp. 37-58.

Wetherell, M., Stiven, H. \& Potter, J. (1987), “Unequal Egalitarianism: A Preliminary Study of Discourses Concerning Gender and Employment Opportunities”, British Journal of Social Psychology, Vol. 26, pp. 59-71 